\title{
Driving ability after right-sided puncture of the common femoral artery during coronary angiography
}

\author{
Christoph Brenner ${ }^{1,4} \oplus \cdot$ Raoul Fuehring $^{1,3} \cdot$ David Niederseer $^{2} \cdot$ Rudolf Kirchmair $^{1} \cdot$ Christian Haid $^{3}$. \\ Michael Liebensteiner ${ }^{3}$
}

Received: 3 March 2018 / Accepted: 16 April 2018 / Published online: 19 April 2018

(c) The Author(s) 2018

\begin{abstract}
Objectives/background To assess brake reaction time (BRT; key factor in driving ability) in patients receiving transfemoral coronary angiography $(\mathrm{CAG})$. We assumed that patients would have a significantly impaired BRT after the procedure.

Methods A prospective, observational study design was applied. Consecutive patients undergoing right-sided transfemoral CAG as part of the clinical routine were included. An experimental driving simulator was used to determine BRT after receiving a visual stimulus. The subjects applied the brake with their right foot as quickly as possible when a red-light signal appeared. The time interval between stimulus and brake application was taken as BRT. In addition to the total BRT, also its components were determined: neurologic reaction time, foot transfer time and brake travel time. BRT was determined before and 1 day after CAG (pre-post comparison).

Results 71 patients were included in the analysis ( 58 male, age $61 \pm 9$ years). Total BRT was $594 \pm 188$ and $591 \pm 198 \mathrm{~ms}$ before and after the CAG procedure, respectively $(p=0.270)$. Similarly, also the BRT components 'foot transfer time' and 'brake travel time' did not show significant differences between the two test occasions. However, neurologic reaction time decreased from $269 \pm 67$ to $255 \pm 64 \mathrm{~ms}(p=0.036)$.

Conclusions We found no impairment of BRT on the first day after puncture of the right-sided femoral artery in patients undergoing CAG. Therefore, with regard to BRT, it is regarded safe to resume driving from day 1 after CAG. Other factors of driving safety beyond BRT must also be considered.
\end{abstract}

Keywords Driving ability $\cdot$ Brake reaction time $\cdot$ Cardiac catheterization $\cdot$ Femoral puncture

Abbreviations

BRT Brake reaction time

CAG Coronary angiography

NRS Numeric rating scale

\section{Introduction}

In the context of standard procedures of the lower limbs, physicians are often confronted with questions regarding driving ability after invasive procedures. Such questions are of obvious importance for patient safety as well as for the
Christoph Brenner

Christoph.brenner@i-med.ac.at; mail@med.cbrenner.net

Raoul Fuehring

Raoul.Fuehring@student.i-med.ac.at

David Niederseer

David.Niederseer@usz.ch

Rudolf Kirchmair

Rudolf.Kirchmair@i-med.ac.at

Christian Haid

Christian.Haid@i-med.ac.at

Michael Liebensteiner

Michael.Liebensteiner@tirol-kliniken.at
Department of Internal Medicine III, Cardiology and Angiology, Medical University of Innsbruck, Anichstr. 35, 6020 Innsbruck, Austria

2 Department of Cardiology, University Heart Center Zurich, University of Zurich, Zurich, Switzerland

3 Department for Orthopaedic Surgery, Medical University of Innsbruck, Innsbruck, Austria

4 Reha Zentrum Muenster and Karl Landsteiner Institute for Interdisciplinary Rehabilitation, Tyrol, Austria 
safety of other traffic participants. Driving ability is crucial for an individual's participation in contemporary social life and an important task in activities of daily living. Therefore, an excessive driving prohibition following interventional or surgical treatment is not useful. When weighing the interests of safety vs. independence, it would be beneficial to have specific scientific knowledge about postoperative driving impairments following invasive medical procedures.

Among the various factors contributing to driving ability (visual acuity, amount of sleep, etc.), previous studies reported "brake reaction time" (BRT) to be a key parameter (synonyms: driving reaction time, brake response time) [1-3]. BRT was defined as the time interval between a (visual) stimulus (e.g. red traffic lights) and the application of sufficient pressure to the brake pedal.

Previous research provided good evidence on driving ability in the context of elective orthopaedic surgery such as total joint arthroplasty [2-8], knee arthroscopy $[9,10]$ or spinal surgery [11-14]. Previous studies also investigated the influence of inguinal hernia repair surgery on BRT [15-17]. For many other invasive standard procedures related to the lower limbs the literature contains little or no evidence on a patient's postoperative BRT or general driving abilities. To the best of our knowledge, no previous studies have investigated the influence of standard vascular surgical procedures (e.g. femoropopliteal bypass surgery) on driving ability. Likewise, inguinal puncture of the right-sided femoral artery (e.g. for endovascular coronary procedures) has not been investigated although pain in the groin might impair driving ability.

Therefore, the purpose of this study was to assess brake reaction time as a key factor in driving ability in patients undergoing puncture and temporary catheter sheath implantation in the right-sided femoral artery for invasive coronary angiography (CAG). We assumed that BRT might be significantly increased after the procedure in our patients (pre-post comparison, Hypothesis 1).

\section{Methods}

\section{Participants}

We designed a prospective, observational study that was approved by the Ethics Committee of our medical university (No. AN2016-0050 360/4.2 367/5.4 (3922a)) and was performed in accordance with the ethical standards laid down in the 1964 Declaration of Helsinki and its later amendments. Consecutive patients undergoing CAG as part of the clinical routine of our university hospital were considered for participation and included after granting written informed consent. The only exclusion criteria were: (a) acute coronary syndrome, (b) no driver's licence, (c) known neurologic diseases that would impair BRT.

\section{Procedure}

Patients with stable angina pectoris scheduled for elective CAG via a transfemoral route were included. All patients were pretreated with $100 \mathrm{mg}$ Aspirin at least the day before and on the day of the procedure. For CAG, we gained vascular access to the right common femoral artery after local anaesthesia with $10 \mathrm{cc} 1 \%$ lidocaine. Using the Seldinger technique we inserted a vascular access sheath (Cordis Avanti ${ }^{\circledR}$ introducer, sized 6 or 7 french) in the femoral artery. Patients undergoing PCI of a coronary artery received a $600 \mathrm{mg}$ loading dose of Clopidogrel and $60-70 \mathrm{IE} / \mathrm{kg}$ of unfractionated Heparin immediately prior to guide wire placement. After PCI, administration of Aspirin and Clopidogrel was continued once daily in all patients until the end of the study. After CAG completion, we removed the sheath and closed the vascular access site using the FemoSeal ${ }^{\mathrm{TM}}$ vascular closure device (St. Jude Medical ${ }^{\circledR}$ ). All patients additionally received an inguinal compression bandage and rested in bed for the following six hours before mobilization. This procedure was identical in all patients regardless if they were treated with PCI or not. Patients with inguinal hematoma ( $>5 \mathrm{~cm}$ diameter), clinically apparent pseudoaneurysm (vascular murmur) or immobilizing pain at the vascular access site were excluded from the follow-up measurement. For study exclusion due to access site complications, we only used clinical assessments. If clinically indicated, color-coded Doppler sonography was used to guide the further treatment strategies.

\section{Outcome parameters}

Based on apparatuses described and validated in the published literature [1,2], we devised an experimental apparatus for measuring BRT (Figs. 1, 2). An adjustable car seat was mounted on a frame with pedals hanging from rubberdamped pivots. The inclination of the seat, the head rest, the seat-to-pedal distance and the seat height were adjusted according to previous investigations [18], such that they resembled the patient's usual driving position. An external suitcase containing the logic gate electronics, and a green and a red lamp was positioned on a table at a fixed distance.

The procedure was commenced by the patient fully depressing the accelerator, which was confirmed when a green lamp lit up. This prevented the patient from driving in a 'ready-to-brake fashion'. After an interval of 5-10 s, the investigator pressed a switch concealed from the patient, which activated the red lamp (visual stimulus for the patient) and the electronic clock. Before starting the procedure, the subjects were instructed in a standardized manner to apply 


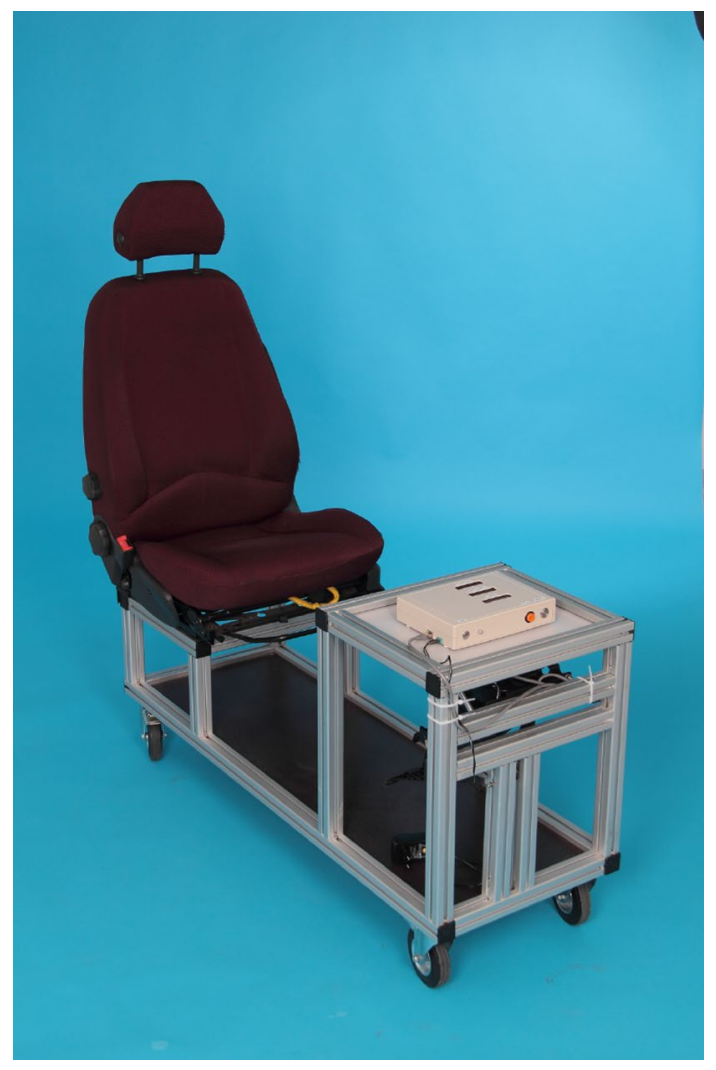

Fig. 1 The driving simulator with an adjustable seat and the electronics. The trigger and a green lamp are orientated towards the observer

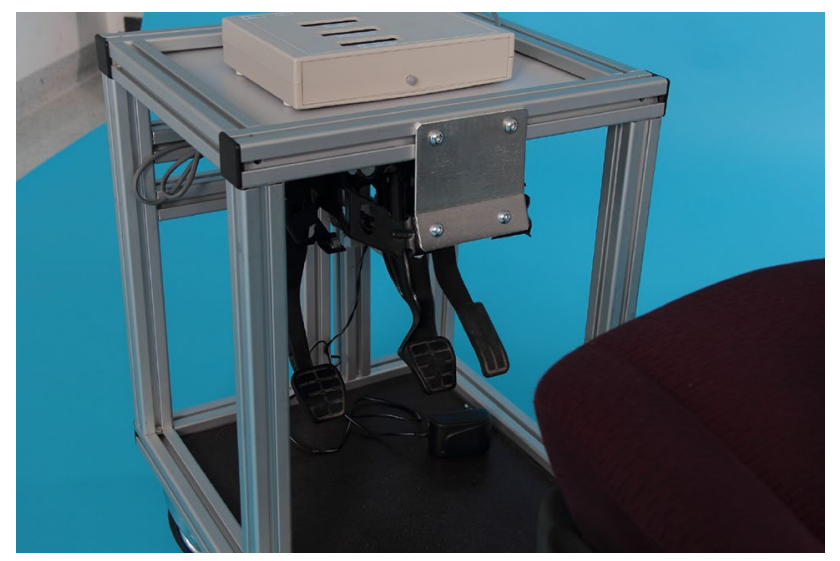

Fig. 2 The box in front of the patient with a red lamp orientated towards the patient

the brake with their right foot as quickly as possible when the red-light signal appeared. The time interval until the subject operated the brake pedal with $160 \mathrm{~N}$ was measured and taken as the BRT.

In addition to the total BRT, the integrated stopwatch also automatically determined individual components of BRT: neurologic reaction time (time from visual stimulus until the subject starts to pull back his foot), foot transfer time (time from start of foot retraction from the accelerator until initial contact with the brake pedal) and brake travel time (time from initial contact with the brake pedal until $160 \mathrm{~N}$ is reached).

Patients exclusively used their right leg to operate the pedals of the apparatus, while the left foot rested on the clutch pedal. After the subject had familiarized himself with the apparatus in three training runs, BRT was measured consecutively 10 times as described. An interval of $5 \mathrm{~s}$ was maintained between measurements. Total BRT and its components were calculated as the arithmetic average of the 10 measurements. All participants were given the same standardized instructions. BRT was determined before CAG to obtain a reference value. Another BRT measurement was performed in all patients on day 1 after CAG. On day 1 after CAG patients also rated their level of inguinal pain on a 10-point numeric rating scale (NRS).

\section{Statistical analysis}

Data analysis was performed with SPSS (International Business Machines Corporation, Armonk, NY, USA). Data were not normally distributed as indicated by the Kolmogorov-Smirnov test. As descriptive values medians and interquartile ranges were determined. Wilcoxon tests were applied to test for significant differences in BRT between measurements 1 and 2. Alpha was defined as 0.05 (two-tailed).

\section{Results}

Eighty-four patients were included and underwent BRT measurement at the first test. Of these patients, 13 did not participate in the second BRT measurement for the following reasons: organizational reasons: four, cancelled CAG: one, haematoma $>5 \mathrm{~cm}$ : three, immobilizing pain: three, refused: two. The remaining 71 patients were included in the analysis (58 male, age $61 \pm 9$ years). Patient characteristics are provided in Table 1.

Total BRT was $594 \pm 188$ and $591 \pm 198 \mathrm{~ms}$ before and after the CAG procedure, respectively $(p=0.270)$. Similarly, also the BRT components 'foot transfer time' and 'brake travel time' did not show significant differences between the two test occasions. However, neurologic reaction time decreased from $269 \pm 67$ to $255 \pm 64 \mathrm{~ms}(p=0.036)$ (Table 2).

\section{Discussion}

The most important finding of the study was that BRT was not impaired on day 1 after puncture of the right-sided femoral artery. Therefore, it is deemed safe to resume driving from day 1 after CAG. 
Table 1 Patient characteristics

\begin{tabular}{|c|c|c|}
\hline & Md & IQR \\
\hline Age (years) & 61 & 9 \\
\hline Weight (kg) & 83.5 & 21.25 \\
\hline Height (cm) & 174 & 11.25 \\
\hline \multirow[t]{2}{*}{$\mathrm{BMI}\left(\mathrm{kg} / \mathrm{m}^{2}\right)$} & 26.8 & 5.1 \\
\hline & Type & $n$ \\
\hline \multirow[t]{3}{*}{ Type of procedure } & Diagnostic & 53 \\
\hline & Interventional & 18 \\
\hline & Number & $n$ \\
\hline \multirow[t]{5}{*}{ Stents implanted } & 0 & 53 \\
\hline & 1 & 11 \\
\hline & 2 & 4 \\
\hline & 3 & 3 \\
\hline & NRS [0-10] & $n$ \\
\hline \multirow{5}{*}{$\begin{array}{l}\text { Inguinal pain on the day after } \\
\text { CAG }\end{array}$} & 0 & 55 \\
\hline & 1 & 12 \\
\hline & 2 & 3 \\
\hline & 3 & 1 \\
\hline & Size & $n$ \\
\hline \multirow[t]{2}{*}{ Sheath } & 6 & 67 \\
\hline & 7 & 4 \\
\hline
\end{tabular}

$C A G$ coronary angiography, $M d$ median, $I Q R$ interquartile range, NRS numeric rating scale

When trying to compare our findings with previous research, it appears that no such studies have been conducted to date. This is surprising because so many other standard medical procedures involving the lower limb have been investigated with regard to BRT. Those studies dealt with inguinal hernia repair [15-17], total hip arthroplasty [2, 5], total knee arthroplasty [3, 6, 8, 19], knee arthroscopy [10] and knee ligament reconstruction [9]. On the basis of their findings, those authors recommended postoperative driving abstinence as follows: 6 days after right-sided open inguinal hernia repair [16], 6-8 weeks after right-sided total hip arthroplasty [2, 5], 6-8 weeks after right-sided total knee arthroplasty [3, 8, 19], 1 week after right-sided knee arthroscopy [10] and 4-6 weeks after right-sided knee ligament reconstruction [9]. It is obvious that the above-mentioned procedures are much more invasive than puncture of the femoral artery with temporary catheter sheath implantation. Therefore, earnest comparison is not possible. Most of the above-mentioned studies used preoperative values as the safety reference, which may be due to the absence of an official reference value. Only some road authorities recommended a maximum BRT ranging between 700 and $1500 \mathrm{~ms}$ [20-22]. Other authors suggested that private drivers be allowed to resume driving $24 \mathrm{~h}$ after $\mathrm{CAG}$, but recommended a 1-month driving abstinence for occupational drivers (lorry, bus, etc.) [23]. However, such recommendations are not based on scientific experiments.

As mentioned above, on the basis of our findings on BRT we do not recommend a ban on driving following right-sided puncture of the femoral artery with temporary catheter sheath implantation. Our findings might also be applicable to patients who undergo puncture of the right-sided femoral artery for endovascular therapy of peripheral arterial occlusive disease. Although we believe that also such patients should be allowed to resume driving, this must be viewed with more caution as we tested only patients who underwent CAG.

We did not analyze left-sided puncture of the femoral artery although invasive procedures of the left leg can potentially affect BRT, as was shown for total knee arthroplasty [7]. The exact mechanism underlying the effect of left-sided total knee arthroplasty on BRT is unclear. A plausible explanation was provided by Pierson et al. [3], who stated that the left leg performs a supportive function when transferring the right foot and is, therefore, involved in the process of braking. This presumed mechanism might be even more relevant in the dynamic circumstances of actual driving (such as negative acceleration during braking). However, as we did not find a significant impairment of BRT after right-sided puncture of the femoral artery, it is also deemed safe to resume driving after left-sided procedures, no matter whether automatic or conventional transmission is concerned.
Table 2 Descriptive and inferential statistics for total brake reaction time (BRT) and its components neurologic reaction time, foot transfer time and brake travel time

\begin{tabular}{|c|c|c|c|c|c|c|c|c|c|}
\hline \multirow[t]{2}{*}{ (ms) } & \multicolumn{4}{|c|}{ Before CAG } & \multicolumn{4}{|c|}{ After CAG } & \multirow[t]{2}{*}{$p$ value } \\
\hline & Md & IQR & Min & $\operatorname{Max}$ & $\mathrm{Md}$ & IQR & Min & $\operatorname{Max}$ & \\
\hline Total BRT & 594 & 188 & 373 & 1612 & 591 & 198 & 413 & 1891 & 0.270 \\
\hline Neurologic reaction time & 269 & 67 & 174 & 577 & 255 & 64 & 174 & 576 & 0.036 \\
\hline Foot transfer time & 224 & 80 & 156 & 545 & 228 & 85 & 147 & 707 & 0.703 \\
\hline Brake travel time & 92 & 100 & 30 & 490 & 96 & 95 & 41 & 608 & 0.806 \\
\hline
\end{tabular}

$C A G$ coronary angiography, BRT brake reaction time, $M d$ median, $I Q R$ interquartile range, $M i n$ minimum, Max maximum 
We detected a slight decrease in neurologic reaction time in the post-CAG measurements compared to the baseline measurements. This difference was presumably based on a certain training effect as the assessments were conducted on two consecutive days. A difference of $14 \mathrm{~ms}$ was found, probably without actual clinical relevance. Additionally, experienced drivers would not experience the described training effect in their own car in real circumstances, i.e. no 14 ms delay due to the initial use of an artificial car simulator.

\section{Study limitations}

The following limitations must be acknowledged. Thirteen patients could not be included in the second BRT measurement, thus giving a drop-out rate of $15 \%$. Therefore, our results must be interpreted with caution. Moreover, the above-mentioned recommendations for patients with endovascular therapy of peripheral arterial occlusive disease must be viewed with even more caution as we tested individuals only following CAG. We studied driving safety only in terms of BRT. Although BRT was described as the most important factor [1], many other skills and factors are, of course, relevant for driving ability and were not investigated in our study [23]. As an example, the risk for stent thromboses after PCI may significantly impact on driving ability but is totally not reflected by the BRT assessed in this study. However, the study provides additional scientific knowledge in a field neglected by previous research.

The study findings are regarded as clinically relevant. No previous studies have investigated driving ability after the standard medical procedure of transfemoral coronary angiography. When weighing the interests of safety vs. independence, it is mandatory to have specific scientific knowledge about postoperative driving impairments following invasive medical procedures. Even if the transradial approach is increasingly used in CAG and BRT is very likely not affected by it, the transfemoral access in CAG is still widely used [24]. We, therefore, feel our results are still of relevance even though the transradial access in CAG is gaining ground.

\section{Conclusions}

We found no BRT impairment on day 1 after puncture of the right-sided femoral artery in patients undergoing CAG. Therefore, with regard to BRT, it is deemed safe for patients to resume driving from day 1 following CAG. Other driving safety factors beyond BRT must also be considered.
Acknowledgements Open access funding provided by University of Innsbruck and Medical University of Innsbruck.

\section{Compliance with ethical standards}

Conflict of interest The authors report no relationships that could be construed as a conflict of interest.

Open Access This article is distributed under the terms of the Creative Commons Attribution 4.0 International License (http://creativeco mmons.org/licenses/by/4.0/), which permits unrestricted use, distribution, and reproduction in any medium, provided you give appropriate credit to the original author(s) and the source, provide a link to the Creative Commons license, and indicate if changes were made.

\section{References}

1. Al-khayer A, Schueler A, Kruszewski G, Armstrong G, Grevitt MP (2008) Driver reaction time before and after treatment for lumbar radiculopathy. Spine 33(15):1696-1700. https://doi. org/10.1097/BRS.0b013e31817b5bb7

2. Ganz SB, Levin AZ, Peterson MG, Ranawat CS (2003) Improvement in driving reaction time after total hip arthroplasty. Clin Orthop Relat Res 413:192-200. https://doi.org/10.1097/01. blo.0000072468.32680.ff

3. Pierson JL, Earles DR, Wood K (2003) Brake response time after total knee arthroplasty: when is it safe for patients to drive? J Arthroplasty 18(7):840-843

4. Marques CJ, Cabri J, Barreiros J, Carita AI, Friesecke C, Loehr JF (2008) The effects of task complexity on brake response time before and after primary right total knee arthroplasty. Arch Phys Med Rehabil 89(5):851-855. https://doi.org/10.1016/j. apmr.2007.10.025

5. MacDonald W, Owen JW (1988) The effect of total hip replacement on driving reactions. J Bone Joint Surg Br 70(2):202-205

6. Liebensteiner MC, Kern M, Haid C, Kobel C, Niederseer D, Krismer M (2010) Brake response time before and after total knee arthroplasty: a prospective cohort study. BMC Musculoskelet Disord 11:267. https://doi.org/10.1186/1471-2474-11-267

7. Marques CJ, Barreiros J, Cabri J, Carita AI, Friesecke C, Loehr JF (2008) Does the brake response time of the right leg change after left total knee arthroplasty? A prospective study. Knee 15(4):295298. https://doi.org/10.1016/j.knee.2008.02.008

8. Liebensteiner MC, Rochau H, Renz P, Smekal V, Rosenberger R, Birkfellner F, Haid C, Krismer M (2014) Brake response time returns to the pre-surgical level 6 weeks after unicompartmental knee arthroplasty. Knee Surg Sports Traumatol Arthrosc 22(8):1926-1931. https://doi.org/10.1007/s00167-014-3050-1

9. Gotlin RS, Sherman AL, Sierra N, Kelly MA, Pappas Z, Scott WN (2000) Measurement of brake response time after right anterior cruciate ligament reconstruction. Arch Phys Med Rehabil 81(2):201-204

10. Hau R, Csongvay S, Bartlett J (2000) Driving reaction time after right knee arthroscopy. Knee Surg Sports Traumatol Arthrosc 8(2):89-92

11. Liebensteiner MC, Birkfellner F, Thaler M, Haid C, Bach C, Krismer M (2010) Driving reaction time before and after primary fusion of the lumbar spine. Spine 35(3):330-335. https://doi. org/10.1097/BRS.0b013e3181b8e11a

12. Thaler M, Lechner R, Foedinger B, Haid C, Kavakebi P, Galiano K, Obwegeser A (2012) Driving reaction time before and after surgery for lumbar disc herniation in patients with radiculopathy. 
Eur Spine J 21(11):2259-2264. https://doi.org/10.1007/s0058 6-012-2378-9

13. Lechner R, Thaler M, Krismer M, Haid C, Obernauer J, Obwegeser A (2013) Driving reaction time before and after anterior cervical fusion for disc herniation: a preliminary study. Eur Spine J 22(7):1517-1521. https://doi.org/10.1007/s0058 6-013-2688-6

14. Thaler M, Lechner R, Foedinger B, Haid C, Kavakebi P, Galiano K, Obwegeser A (2015) Driving reaction time before and after surgery for disc herniation in patients with preoperative paresis. Spine J 15(5):918-922. https://doi.org/10.1016/j.spine e.2013.06.052

15. Bahir A, Lawaetz O, Kjeldsen L, Lund P (2001) Convalescence and driver reaction time after tension-free inguinal hernia repair. Ambul Surg 9(1):19-21

16. Wright DM, Hall MG, Paterson CR, O’Dwyer PJ (1999) A randomized comparison of driver reaction time after open and endoscopic tension-free inguinal hernia repair. Surg Endosc 13(4):332-334

17. Wilson MS, Irving SO, Iddon J, Deans GT, Brough WA (1998) A measurement of the ability to drive after different types of inguinal hernia repair. Surg Laparosc Endosc 8(5):384-387

18. Scott PA, Candler PD, Li JC (1996) Stature and seat position as factors affecting fractionated response time in motor vehicle drivers. Appl Ergon 27(6):411-416
19. Spalding TJ, Kiss J, Kyberd P, Turner-Smith A, Simpson AH (1994) Driver reaction times after total knee replacement. J Bone Joint Surg Br 76(5):754-756

20. Burckhardt M (1985) Reaktionszeiten bei Notbremsvorgangen. TUV, Rheinland, Cologne

21. Department of Transport COI (1978) The highway code. Her Majesty's Stationery Office, London

22. Royal Automobile Club of Victoria (1996) Average reaction, braking and stopping distances in metres at different speed with reaction time of $0.75 \mathrm{~s}$. Royal Automobile Club of Victoria, Melbourne

23. Klein HH, Krämer A, Pieske BM, Trappe HJ, De Vries H (2010) Positionspapier Fahreignung bei kardiovaskulären Erkrankungen. Der Kardiologe 4(6):441-473

24. Feldkamp T, Luedemann M, Spehlmann ME, Freitag-Wolf S, Gaensbacher J, Schulte K, Bajrovic A, Hinzmann D, Hippe HJ, Kunzendorf U, Frey N, Luedde M (2018) Radial access protects from contrast media induced nephropathy after cardiac catheterization procedures. Clin Res Cardiol 107(2):148-157. https://doi. org/10.1007/s00392-017-1166-2 